Research Paper

\title{
Antibiotic Elution and Mechanical Strength of PMMA Bone Cement Loaded With Borate Bioactive Glass
}

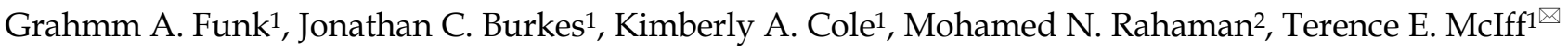 \\ 1. Department of Orthopedic Surgery, University of Kansas Medical Center, Kansas City, KS, United States \\ 2. Department of Materials Science and Engineering, Missouri University of Science and Technology, Rolla, MO, United States \\ $\square$ Corresponding author: Prof. Terence McIff, University of Kansas Medical Center, 3901 Rainbow Blvd. M.S. 3031, Kansas City, KS, USA. Phone: +1 913588 \\ 3175; Fax: +1 913588 0070; Email: TMCIFF@kumc.edu \\ (c) Ivyspring International Publisher. This is an open access article distributed under the terms of the Creative Commons Attribution (CC BY-NC) license \\ (https://creativecommons.org/licenses/by-nc/4.0/). See http://ivyspring.com/terms for full terms and conditions.
}

Received: 2018.05.18; Accepted: 2018.08.06; Published: 2018.09.07

\begin{abstract}
Introduction: Local delivery of antibiotics using bone cement as the delivery vehicle is an established method of managing implant-associated orthopedic infections. Various fillers have been added to cement to increase antibiotic elution, but they often do so at the expense of strength. This study evaluated the effect of adding a borate bioactive glass, previously shown to promote bone formation, on vancomycin elution from PMMA bone cement.

Methods: Five cement composites were made: three loaded with borate bioactive glass along with 0,1 , and 5 grams of vancomycin and two without any glass but with 1 and 5 grams vancomycin to serve as controls. The specimens were soaked in PBS. Eluate of vancomycin was collected every 24 hours and analyzed by HPLC. Orthopedic-relevant mechanical properties of each composite were tested over time.

Results: The addition of borate bioactive glass provided an increase in vancomycin release at Day 1 and an increase in sustained vancomycin release throughout the treatment period. An $87.6 \%$ and $21.1 \%$ increase in cumulative vancomycin release was seen for both $\mathrm{lg}$ and $5 \mathrm{~g}$ loading groups, respectively. Compressive strength of all composites remained above the weight-bearing threshold of $70 \mathrm{MPa}$ throughout the duration of the study with the glass-containing composites showing comparable strength to their respective controls.

Conclusion: The incorporation of borate bioactive glass into commercial PMMA bone cement can significantly increase the elution of vancomycin. The mechanical strength of the cement-glass composites remained above $70 \mathrm{MPa}$ even after soaking for 8 weeks, suggesting their suitability for orthopedic weight-bearing applications.
\end{abstract}

Key words: borate glass, bioactive glass, vancomycin, elution, strength

\section{Introduction}

Periprosthetic joint infections are considered one of the most serious complications following orthopedic procedures. Studies of the Medicare population between 1997 and 2006 found the risk of infection within the first two years following total joint replacement to be $1-2 \% .[1,2]$ Treatment often requires prolonged systemic and local delivery of antibiotics. Local antibiotic delivery is usually done by injection, sprinkling into the open wound, or delivery from an implanted device, the most common of which is bone cement. While it may not be the best drug delivery vehicle, bone cement is used by surgeons to deliver antibiotics because it is often already at the site of infection in the form of temporary spacers, bone void filler, or for implant anchorage.

The addition of antibiotics to bone cement was successfully introduced as a means to treat infection 
around prosthetic joints in 1970.[3] Until 2003, when the first commercially available preloaded antibiotic bone cement became available, surgeons added antibiotics to the cement during mixing in the OR.[4] Given the limited variety of antibiotics preloaded within commercial bone cement, surgeons often add additional antibiotics or other antimicrobial components into bone cement in the OR. The aminoglycosides gentamicin and tobramycin are the most common antibiotics commercially preloaded into bone cement, while vancomycin is the most common antibiotic added to cement in the OR.

Poly(methyl methacrylate) (PMMA), one of the most widely used thermoplastic acrylics, has been used as a base for bone cement since the 1940s.[5] Although routinely used and recognized as an effective drug delivery vehicle, PMMA-based bone cement typically elutes merely a small fraction of the antimicrobials that are mixed into it, almost all of which is released during the first few days.[6] PMMA hardens to form an inherently impermeable, nonresorbable, hydrophobic, and low-porosity solid that is not optimal for the delivery of drugs. However, despite its hydrophobicity, PMMA and PMMA-based bone cement can still absorb up to as much as $2 \%$ water by weight.[7-9] This fluid absorption and exchange allows for some of the drug molecules to escape from the confines of the PMMA matrix, but primarily only those near the surface of the cement. One approach to increasing antibiotic delivery might be to simply increase the amount of antimicrobial mixed into the cement. However, drug incorporation into cement can be limited by the additive's negative effect on the cement's mechanical strength, workability, setting time, or other properties.[10,11]

Numerous techniques and additives have been evaluated as a means of increasing bone cement's elution of antibiotics while subsequently trying to maintain the mechanical properties necessary for its use as a load-bearing cement. Increasing porosity or inhomogeneity of bone cement composites has been a primary goal. Mixing without vacuum or delaying the mixing until the cement has partially polymerized has been shown to promote increased elution of antibiotics.[12] A combination of additives can also be used to increase elution. Penner et al. showed that the addition of tobramycin and vancomycin together into PMMA as opposed to adding either alone increased the elution of both antibiotics from PMMA.[13] Other techniques for increasing elution have focused on adding various materials to function as porogens, such as polymers or bioactive glasses.[14] The addition of a bioresorbable filler to the bone cement creates the possibility of increasing cement porosity over time as the filler resorbs, leaving behind channels for drug escape. Xylitol and chitosan have been studied for their use as bioresorbable porogens within PMMA and have been shown to increase drug elution from the cement at the cost of decreased cement strength.[15,16]

Silicate and borate bioactive glasses are the most common bioactive glasses to be used in medicine.[17] The original silicate bioactive glass formulation, Bioglass 45S5, was first formulated in 1969 by Dr. Larry Hench and has since been studied extensively.[18,19] Silicate-free borate bioactive glass was introduced in 2005 as an alternative bioactive glass for cell-based bone tissue engineering scaffolds.[20,21] These bioactive glasses have several properties that make them potentially useful in bone healing and infection sites. First, they support local bone growth. As the bioactive glass particles dissolve in vivo, the ions released from the glass support osteogenic activity, promoting healing.[22,23] Second, once released, calcium and phosphate ions from the glass combine with local ions to form a hydroxyapatite (HA)-like layer on the material's surface that has the ability to bond with hard and soft tissues, including bone.[24,25] Third, bioactive glasses can be antimicrobial themselves and have been shown to be bactericidal either alone or when doped with trace quantities of elements known to have antimicrobial effects such as silver, gallium, or iodine.[26-28]

Studies have suggested that bioactive glass may aid in local antibiotic delivery from cement as well as in bone regeneration.[26] A previous study by $\mathrm{D}$. Arcos et al. investigated the addition of silicate bioactive glass to acrylic bone cement.[29] They found that this combination could be used to control antibiotic elution, and that the presence of bone cement and gentamicin did not affect the bioactive behavior of the glass. Compared to silicate-based bioactive glass, borate bioactive glasses degrade faster and convert more completely to an HA-like layer due to their lower chemical durability and higher aqueous solubility.[25,30] For this reason, borate bioactive glass may be a better candidate than silicate glass to increase antibiotic delivery from bone cement.

Given the potential advantages, this study sought to evaluate whether adding borate bioactive glass to PMMA bone cement would increase the rate of antibiotic elution while maintaining the cement's mechanical strength. We hypothesized that PMMA-based bone cement with incorporated bioactive glass would increase the total elution of vancomycin for both low and high vancomycin loads and that the mechanical strength would not be reduced below the $70 \mathrm{MPa}$ ISO standard.[31] 


\section{Methods}

\section{Cement Composite Preparation}

The bone cement used was SmartSet MV (DePuy, Warsaw, IN, USA). The cement was sterile and used prior to its expiration date. Medical grade vancomycin - $\mathrm{HCl}$ powder was obtained from Fagron, Inc. through Sigma-Aldrich.

Borate bioactive glass (13-93B3) was prepared at and obtained from Missouri University of Science and Technology (Dr. Mohamed Rahaman). 13-93B3 (mol\%: $6 \mathrm{Na}_{2} \mathrm{O}, 7.9 \mathrm{~K}_{2} \mathrm{O}, 7.7 \mathrm{MgO}, 22.1 \mathrm{CaO}, 54.6 \mathrm{~B}_{2} \mathrm{O}_{3}$, $\left.1.7 \mathrm{P}_{2} \mathrm{O}_{5}\right)$ was prepared by mixing $\mathrm{Na}_{2} \mathrm{CO}_{3}, \mathrm{~K}_{2} \mathrm{CO}_{3}$, $\mathrm{MgCO}_{3}, \mathrm{CaCO}_{3}, \mathrm{NaH}_{2} \mathrm{PO}_{4} \cdot 2 \mathrm{H}_{2} \mathrm{O}$, and $\mathrm{H}_{3} \mathrm{BO}_{3}$ (Fisher Scientific) together and heating the mixture to $1100^{\circ} \mathrm{C}$ for 1 hour inside a platinum crucible, which was then quenched between steel plates at room temperature $\left(23^{\circ} \mathrm{C}\right)$. The glass was crushed to a diameter of $5 \mu \mathrm{m}$ by grinding $100 \mathrm{~g}$ of glass frits for 150 seconds in a steel shatterbox (8500 Shatterbox, Spex SamplePrep $\mathrm{LL}$, Metuchen, NJ). The glass was then ground for 90 minutes in an attrition mill (Model 01-HD, Union Process, Akron, $\mathrm{OH})$. Once dried, the glass was ground with a mortar and pestle and then sieved though a stainless steel sieve. Particle size analysis, performed using a Microtrac S3000 particle size analyzer, showed the glass had an average size of 5 $\mu \mathrm{m}$ with a standard deviation of $3 \mu \mathrm{m}$.

Five cement groups were prepared, each with different compositions (Table 1). For each group the dry cement component $(40 \mathrm{~g})$ was mixed with a set amount of borate bioactive glass and/or vancomycin powder using a manual mixer without vacuum at the rate of 1 rotation per sec until uniform. The $20-\mathrm{mL}$ liquid monomer component was then added and further mixed at $1 \mathrm{~Hz}$ for 90 seconds.

Following mixing, the above groups were checked for the doughing stage every 15 seconds as per ASTM standard F451-16.[32] Once the doughing stage was achieved, they were then placed into a polytetrafluoroethylene (PTFE) mold, yielding $6 \mathrm{~mm}$ by $12 \mathrm{~mm}$ cylinders. The mold was placed into an incubator held at $37^{\circ} \mathrm{C}$ for one hour to allow cement curing. Afterwards, the cement cylinders were removed from the mold and inspected for significant defects. Defective cylinders were discarded.

\section{Elution Testing}

Ten specimens from each group were each placed separately into $15-\mathrm{mL}$ polypropylene tubes to which $2.5 \mathrm{~mL}$ of phosphate-buffered saline (PBS, $\mathrm{pH}=7.4$, Ricca Chemical, Arlington, TX) was added, allowing enough volume to cover the entirety of the specimens. The tubes were sealed and placed within an incubator at $37^{\circ} \mathrm{C}$. Elution collection was performed every 24 hours and carried out for 2 weeks for V1 and BGV1. Elution collection was extended to 4 weeks for V5 and BGV5. The residual PBS was discarded and replenished after each collection. The vancomycin concentration of each eluate was analyzed using a Shimadzu 10 series HPLC with a Hypersil GOLD C18 column $(5 \mu \mathrm{m}, 250 \times 4.6 \mathrm{~mm})$. Isocratic elution was performed with a mobile phase consisting of water-acetonitrile-100 $\mathrm{mM}$ ammonium acetate (composite ratio, 78/12/10 $\mathrm{v} / \mathrm{v} / \mathrm{v} \%$ ), adjusted to a $\mathrm{pH}$ of 5.4.[33] Detection wavelength was set to $214 \mathrm{~nm}$. The mobile phase was prepared daily. Standard vancomycin calibration curves were prepared with each mobile phase preparation. The concentration of vancomycin was determined by recording elution peaks, baseline correction with control (BG), and matching the value to the corresponding standard curve. Analysis was performed using MATLAB (MathWorks, Natick, MA).

Since a standard commercial bone cement kit containing $40 \mathrm{~g}$ of powder and $18.88 \mathrm{~g}$ of monomer was used as the basis for this study, the addition of the glass to groups BGV1 and BGV5 lowered the weight ratio of vancomycin in these groups relative to $\mathrm{V} 1$ and V5. To compensate for this difference in vancomycin content, a correction factor was applied to the groups containing bioactive glass and used when comparing relative elution (10.59\% in BGV1 and 6.47\% in BGV5). This correction factor was based on the measured average weight of the pellets in each group and the calculated amount of vancomycin in each pellet. The vancomycin in each pellet is equivalent to [ (avg. wt. of pellet in group) $x$ (vancomycin in batch)]/batch weight. This yielded a conservative correction factor for comparing elution from pellets having different vancomycin content due to the addition of glass.

Table 1. The compositions of the antibiotic- and glass-loaded cement groups studied.

\begin{tabular}{lllllll}
\hline $\begin{array}{l}\text { Sample } \\
\text { Group }\end{array}$ & $\begin{array}{l}\text { Vancomycin } \\
(\mathrm{g})\end{array}$ & $\begin{array}{l}\text { Glass } \\
(\mathrm{g})\end{array}$ & $\begin{array}{l}\text { SmartSet MV Powder } \\
(\mathbf{g})\end{array}$ & $\begin{array}{l}\text { Liquid Component } \\
(\mathrm{g})\end{array}$ & $\begin{array}{l}\text { Vancomycin Component } \\
(\mathbf{w t .} \%)\end{array}$ & $\begin{array}{l}\text { Glass Component } \\
(\text { wt.\%) }\end{array}$ \\
\hline BG & 0 & 10 & 40 & 18.88 & 0 & $\begin{array}{l}\text { Specimen Avg. Mass } \\
(\mathbf{g})\end{array}$ \\
V1 & 1 & 0 & 40 & 18.88 & 1.67 & 0.4358 \\
V5 & 5 & 0 & 40 & 18.88 & 7.83 & 0.4182 \\
BGV1 & 1 & 10 & 40 & 18.88 & 1.43 & 0.4036 \\
BGV5 & 5 & 10 & 40 & 18.88 & 6.77 & 0.4413 \\
\hline
\end{tabular}




\section{Compression Testing}

The compressive properties of samples from each group were determined using an MTS Mini Bionix 858 loadframe with MTS Series $793^{\mathrm{TM}}$ Control Software (MTS Systems Corporation, 14000 Technology Drive, Eden Prairie, MN). Data was collected at $20 \mathrm{~Hz}$. Five random samples from each group were tested in compression after having soaked at $37^{\circ} \mathrm{C}$ for $0,1,2,3,4$, and 5 weeks for BG, V1, and BGV1 and for $0,2,4,6$, and 8 weeks for V5 and BGV5 with daily change-out of PBS. Testing was done at a loading rate of $20 \mathrm{~mm} / \mathrm{min}$ to either $40 \%$ strain or fracture, whichever occurred first. Fracture was considered to have occurred when the load fell to below $90 \%$ of its peak value. The compressive strength of the pellets was defined as the failure load divided by the cross-sectional area of the pellets. The failure load was taken as either the load at the $2.0 \%$ offset from the elastic section of the stress-strain curve, the ultimate yield load, or the load at fracture, whichever occurred first. Young's modulus was defined as the slope of the elastic section of the material's stress-strain curve. The ISO 5833 and ASTM F451 standards for the compressive strength of acrylic bone cement (minimum of $70 \mathrm{MPa}$ ) were used as a comparative threshold.[31,32]

\section{Statistical Analysis}

For daily elution, post-hoc unpaired t-tests were used to find significant intra-day differences between groups with equal variance, and Welch's t-test was used for data sets with unequal variances. For total elution, univariate ANOVAs were used to test for significant effects of the groups' compositions. The compressive strengths and Young's moduli of the studied groups were also compared using unpaired t-tests for equal variances and Welch's t-test for unequal variances. The variances of values were considered unequal if the larger variance was more than three times the smaller variance.

\section{Results}

\section{Vancomycin Elution}

The daily elution profiles of both the $1 \mathrm{~g}$ and $5 \mathrm{~g}$ groups are shown below in Figure 1 and Figure 2, respectively. For the $1 \mathrm{~g}$ groups, BGV1 showed significantly greater cumulative vancomycin elution $(p<0.001)$. A significant difference was seen in elution vancomycin concentration at every day until Day 10 $(p<0.05)$. For the $5 g$ groups, BGV5 again showed significantly greater cumulative elution of vancomycin compared to V5 $(\mathrm{p}<0.001)$. A significant difference was seen in elution vancomycin concentration for every day except D11, D12, D14, D16, D18, D20, D26, and D28 ( $\mathrm{p}<0.05)$. At Day 1, BGV1 concentration was $76.48 \%$ greater than that of V1 $(p<0.001)$ and BGV5 had a $17.42 \%$ greater concentration than V5 $(p<0.001)$. The total mass of vancomycin released over the elution duration for all groups is compared in Figure 3. BGV1 released $87.56 \%$ more vancomycin by mass than V1 over 14 days. BGV5 released $20.76 \%$ and $21.10 \%$ more vancomycin by mass than V5 over the course of 14 and 28 days, respectively. The cumulative release of vancomycin as a percentage of vancomycin release vs. vancomycin incorporated is shown in Figure 4. BGV1 was able to release the greatest percentage of its loaded vancomycin.

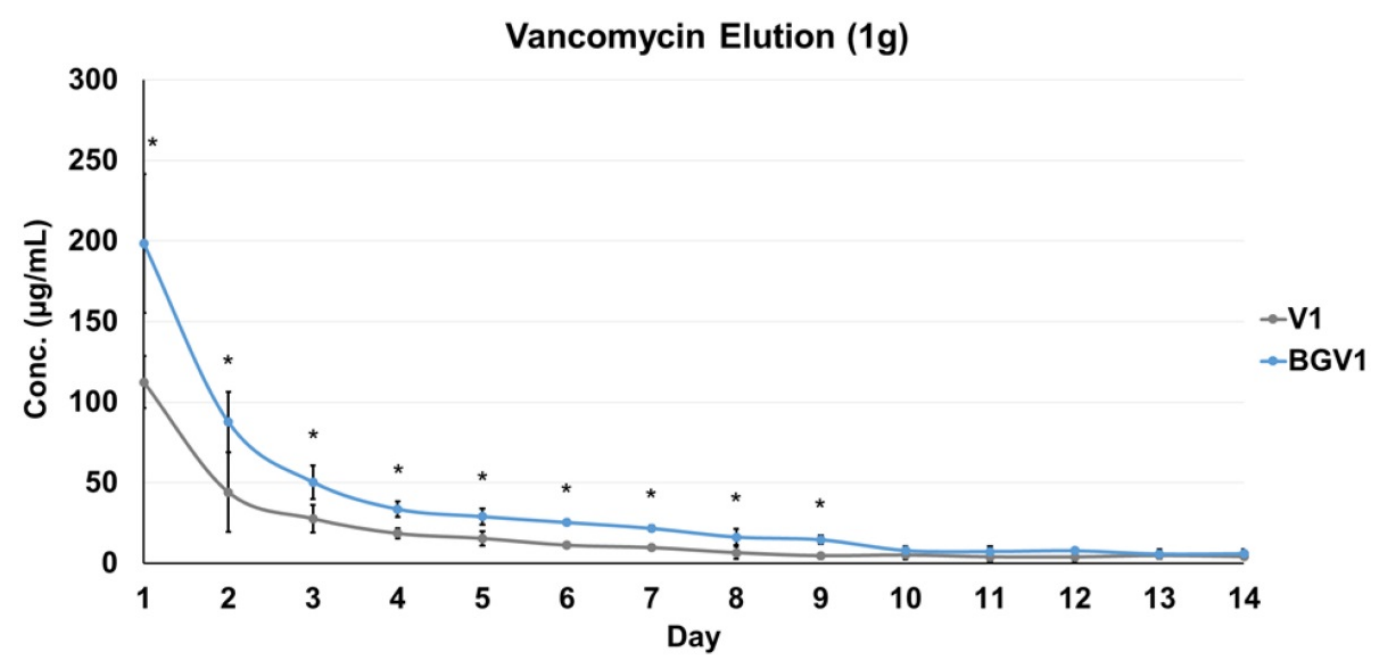

Figure 1. Vancomycin concentration of daily eluate for $\lg$ groups $(n=10)$. An asterisk $(*)$ above a data point indicates a significant difference $(p<0.05)$ between $B G V 1$ and $\mathrm{VI}$. Error bars indicate \pm one standard deviation from the mean. 


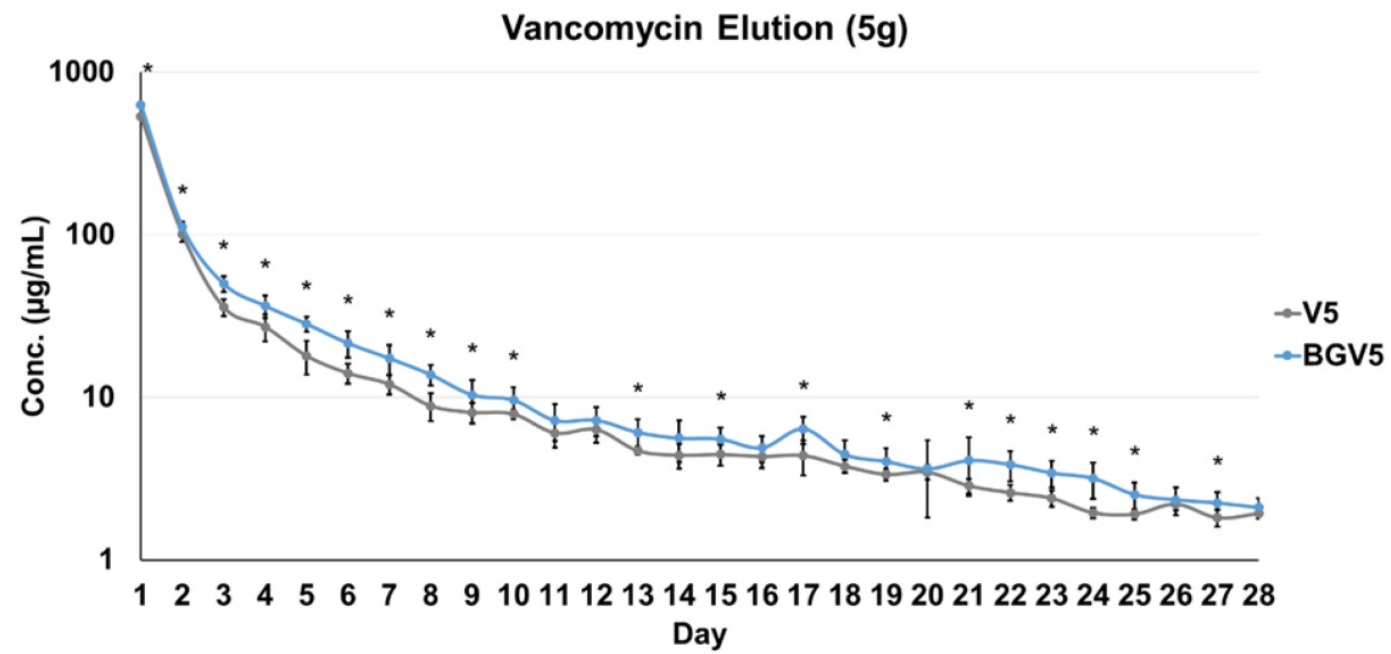

Figure 2. Vancomycin concentration of daily eluate for $5 g$ groups $(n=10)$ on a log scale. An asterisk $(*)$ above a data point set indicates a significant difference $(p<0.05)$ between BGV5 and V5. Error bars indicate \pm one standard deviation from the mean.

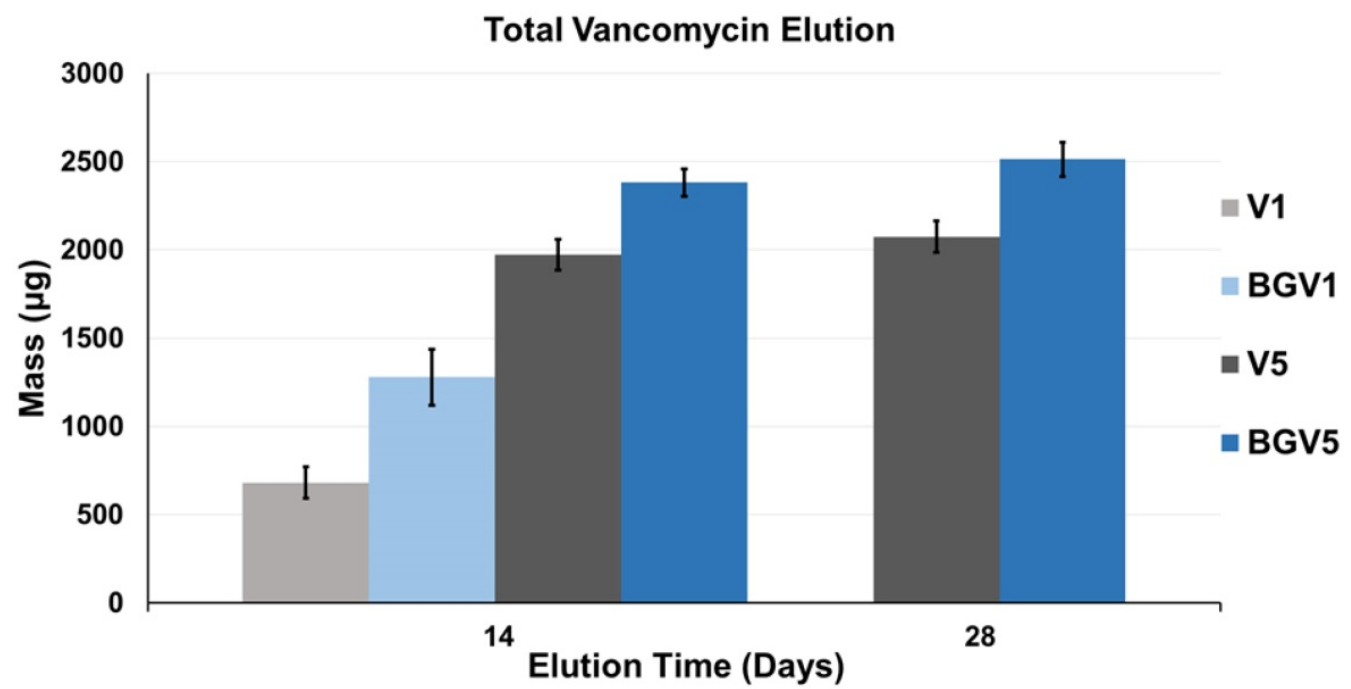

Figure 3. Average total elution of vancomycin over 14 days for all groups, and 28 days for V5 and BGV5. Error bars indicate \pm one standard deviation from the mean ( $\mathrm{n}=10$ ).

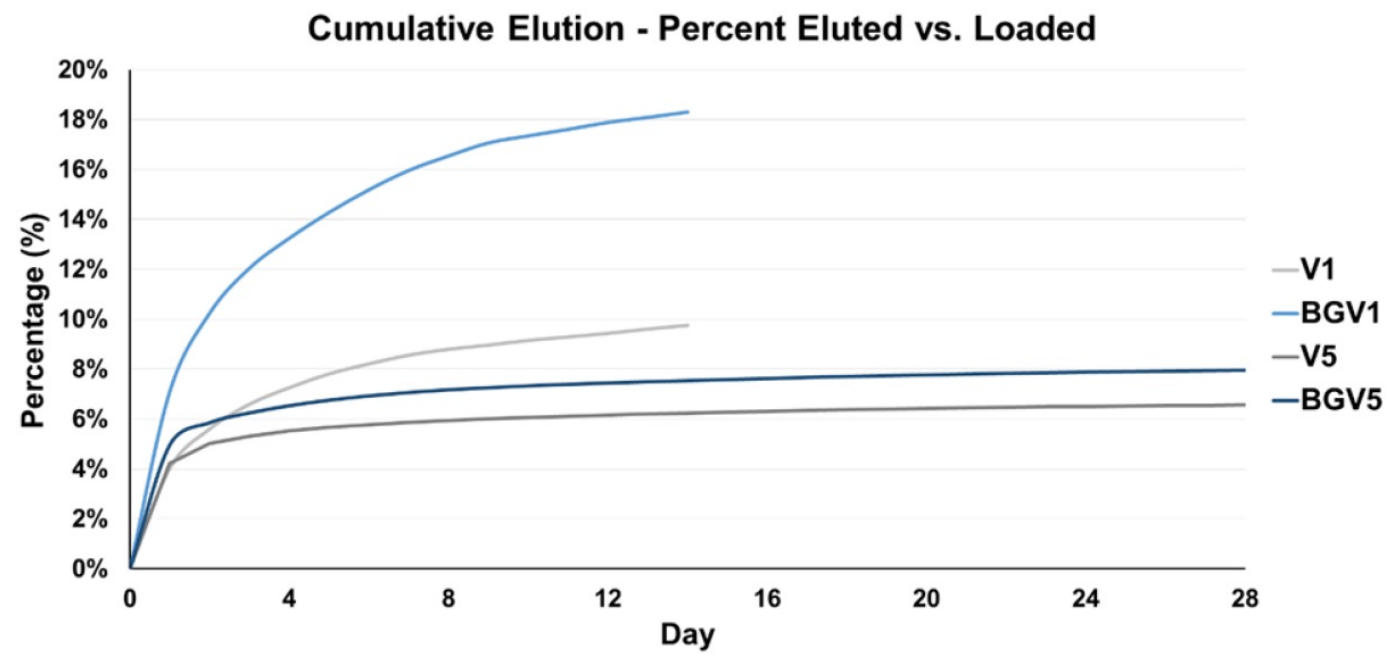

Figure 4. Cumulative average of vancomycin eluted from each group $(n=10)$ as a percentage of vancomycin contained within each group over the treatment period. 


\section{Mechanical Characterization}

The compressive strengths of V1, BG, and BGV1 are shown in Figure 5. The compressive strengths of V5 and BGV5 are shown in Figure 6. Significant differences were noted for $\mathrm{V} 1$ and BGV1 at days 7 and 21 , for V1 and BG at days 21 and 28, and for BG and BGV1 at day 7. Throughout the duration, no group's compressive strength fell below $70 \mathrm{MPa}$. All groups recorded their max strength at Day 0 with steady decline throughout the treatment period. Significant differences were noted between V5 and BGV5 at Day 0,42 , and 56. Throughout the duration, neither group's compressive strength fell below $70 \mathrm{MPa}$. Both groups had the highest compressive strength at Day 0, which then fell for throughout the treatment period. Separate single-factor ANOVAs were run for $1 \mathrm{~g}$ and $5 \mathrm{~g}$ groups which revealed that both time and bioactive glass addition were found to significantly affect compressive strength $(\mathrm{p}<0.05)$.

The Young's modulus for the $1 \mathrm{~g}$ groups and $5 \mathrm{~g}$ groups are displayed in Figure 7 and Figure 8, respectively. Young's modulus slowly decreased over time for both groups, similar to compressive strength. Significant differences between V5 and BGV5 were detected 14, 28, and 42 days after the beginning of soaking. Separate single-factor ANOVAs were run for $1 \mathrm{~g}$ and $5 \mathrm{~g}$ groups which revealed that both time and bioactive glass addition were found to significantly affect Young's modulus ( $\mathrm{p}<0.05)$.

\section{Discussion}

An advantage of locally delivered antibiotics is that a higher concentration of drug can be achieved at the site of concern without the toxicity of orally or intravenously administered antibiotics.[34,35] A major concern associated with antibiotic-laden bone cement is the ability of pathogens to develop drug resistance upon sustained exposure to low local concentration of drug, specifically when below the Minimum Inhibitory Concentration (MIC).[36-38] By increasing the sustained release of a drug from bone cement, it becomes less likely a pathogen will be exposed to below MIC conditions before infection clearance.

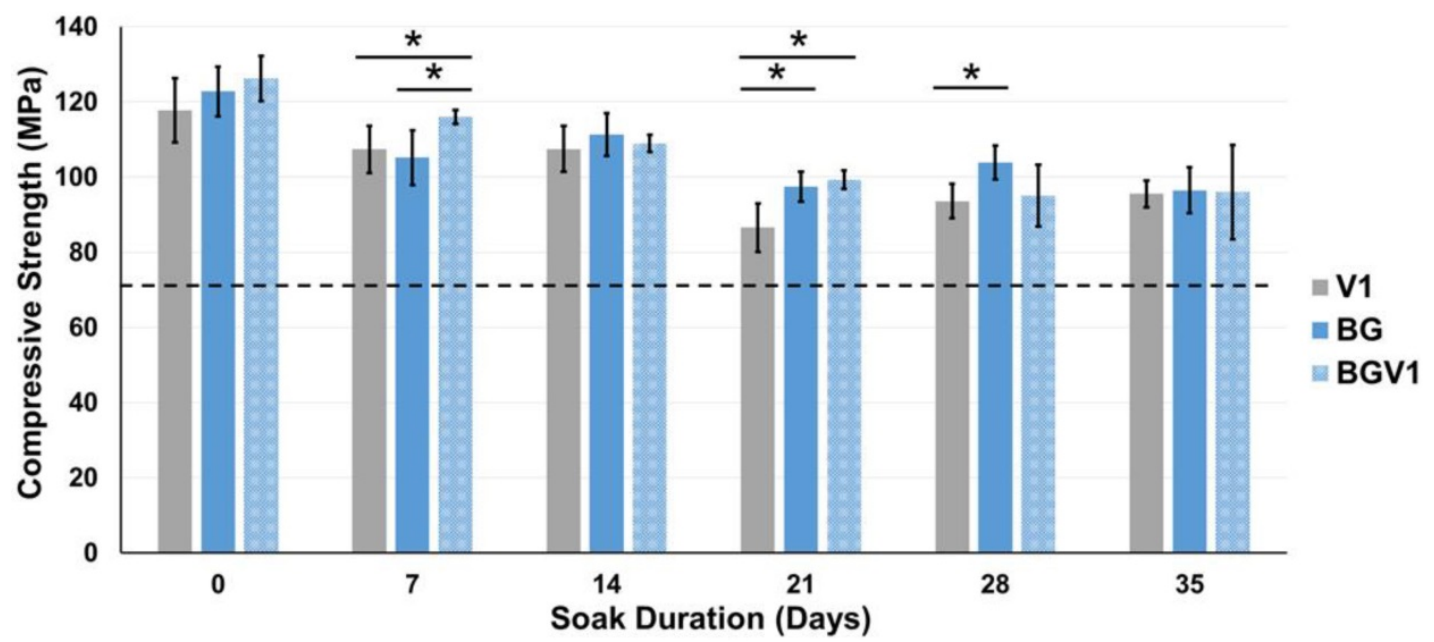

Figure 5. The compressive strengths of $\mathrm{V} 1, \mathrm{BG}$, and BGV1 over time. An asterisk $(*)$ over a bar represents a significant difference $(p<0.05)$ between the groups $(n=5)$ at the ends of the bar. Error bars represent \pm one standard deviation. The dashed line indicates the $70 \mathrm{MPa}$ threshold.

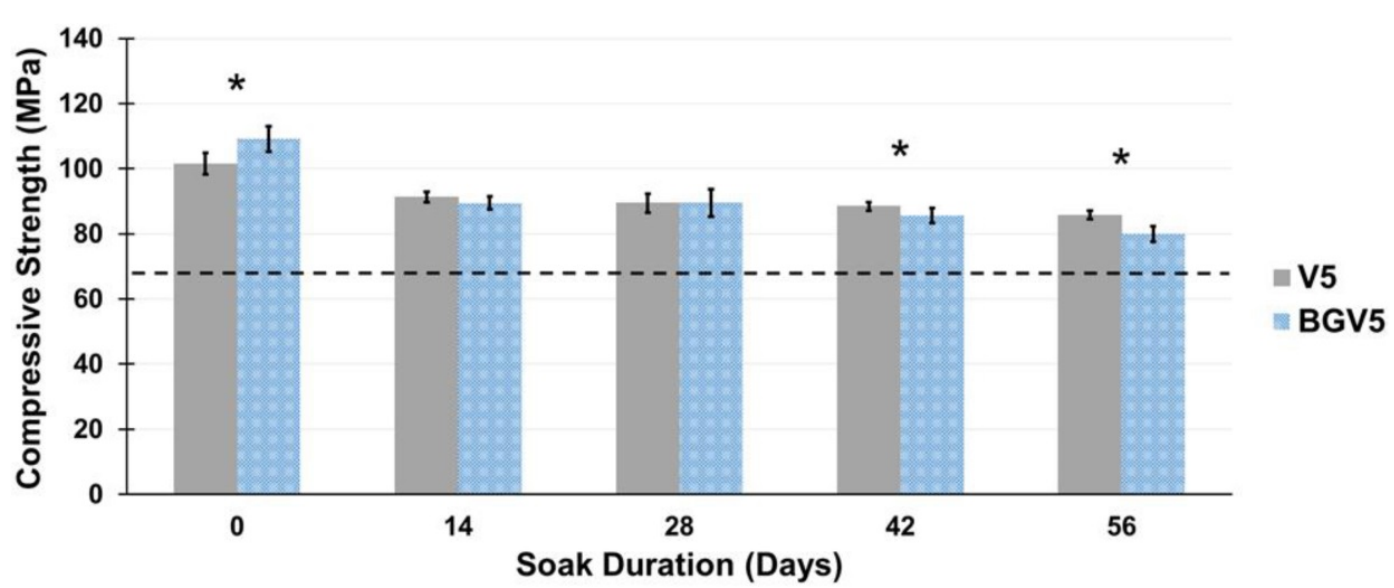

Figure 6. The compressive strengths of $\mathrm{V} 5$ and BGV5 over time. An asterisk $(*)$ above a time point represents a significant difference $(p<0.05)$ between the groups $(n=5)$ at that time duration. Error bars represent \pm one standard deviation. The dashed line indicates the $70 \mathrm{MPa}$ threshold. 


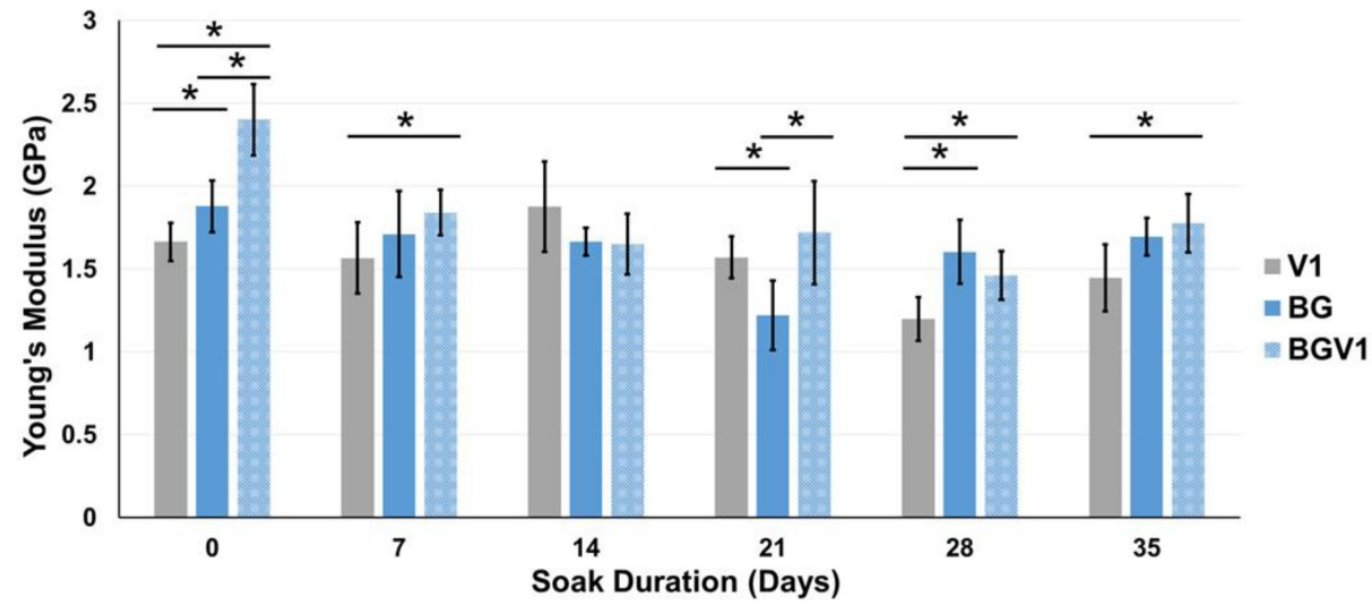

Figure 7. The Young's moduli of V1, BG, and BGV1 over time. An asterisk $(*)$ over a bar represents a significant difference $(p<0.05)$ between the groups $(n=5)$ at the ends of the bar. Error bars represent \pm one standard deviation.

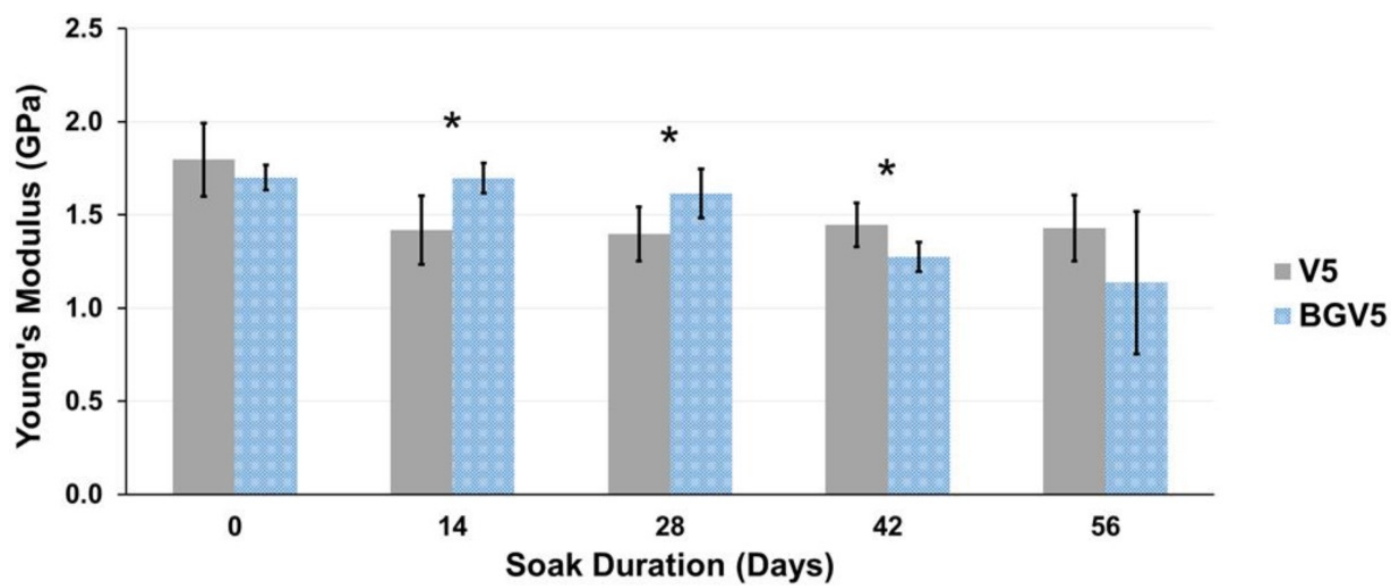

Figure 8. The Young's moduli of V5 and BGV5 over time. An asterisk $(*)$ above a time point represents a significant difference $(p<0.05)$ between the groups ( $n=5)$ at that time duration. Error bars represent \pm one standard deviation.

Little is known about the role of a water soluble glass in aiding antibiotic elution from cement. It is believed that as the solution penetrates into the cement it comes into contact with the soluble glass. The dissolved glass solution moves towards areas of less concentration, creating larger pores and carrying along with it the antibiotic.[39,40] While inert fillers can improve antibiotic elution, bioactive fillers can serve further beneficial purposes within the context of the bone-cement-implant interface. As the bioactive glass dissolves, its components precipitate back onto the surface as calcium phosphate, which crystallizes into hydroxyapatite.[41]

The addition of borate bioactive glass into bone cement functions as a water soluble porogen that allows for significant increases in vancomycin elution from the cement. Even with a modest glass loading percentage (13-15, wt.\%), both groups loaded with either $1 \mathrm{~g}$ or $5 \mathrm{~g}$ of vancomycin outperformed their respective controls. The perceived mechanism lending to this increase in elution was mentioned earlier, being that the dissolved glass would allow for further fluid contact and exchange with the previously entrapped drug. Interestingly, when comparing the percentage of vancomycin eluted compared to the amount loaded into each group, BGV1 released nearly double that of all other groups. As the loading of vancomycin increases, diminishing returns are observed in terms of vancomycin release percentage.

Concerns have been raised over the potential cytotoxicity of borate bioactive glass, and the inhibition of cellular growth by boron has been seen in some in vitro tests.[25,42] However, these same issues have not been seen in vivo, possibly due to the dynamic nature of the environment and the body's ability to metabolize and transport boron ions away from the site before they can collect enough in areas to create cytotoxic concentrations.[42] Jia et al. performed an in vivo rabbit infection experiment in which they implanted borate bioactive glass loaded with teicoplanin at $10 \% \mathrm{w} / \mathrm{w} \%$. They found superior osteogenic and bone healing responses compared to that of calcium sulfate loaded with teicoplanin and reduced MRSA cultures compared to those treated intravenously.[43] 
For all groups, the compressive strength was higher than the ASTM and ISO minimum standard of $70 \mathrm{MPa}$, even after 35 and 56 days of soaking. When significantly different from BGV1 or BG, V1 had lower compressive strengths, revealing the reinforcing effect provided by the glass. BGV5 had a significantly higher compressive strength than V5 at Day 0 but slowly fell below V 5 by Day 42 and 56 of soaking. This could be attributed to the increased mass loss from elution of both the drug and glass over a long period in aqueous solution. The moduli for all groups remained below an average of $2.5 \mathrm{GPa}$. This low moduli can help prevent stress shielding from a mismatch in bone and implant mechanical properties.[44]

Three previous papers have been published on glass-antibiotic-PMMA composites.[29,45,46] None of these used borate bioactive glass or evaluated changes in composite strength over time after exposure to fluid. The primary focus of these studies appeared to be directed toward characterization and development of cement-filler composites for low strength applications, whereas we focused on maintenance of mechanical properties for load-bearing applications with a relatively low filler amount.

Arcos et al. demonstrated gentamicin release from a silicate glass $\left(\mathrm{SiO}_{2}-\mathrm{CaO}-\mathrm{P}_{2} \mathrm{O}_{5}\right) / \mathrm{PMMA}$ composite material but primarily investigated whether the presence of the antibiotic and PMMA had any substantial effect on the bioactivity of the glass.[29] Ragel et al. also characterized cement composites using the same bioactive glass as Arcos but with the addition of poly(L-lactic acid) (PLA).[45] As did Arcos, Ragel characterized the formation of HA onto the composite's surface but did not measure material strength or compare the antibiotic elution achieved to any control or other composite. When compared to the results reported in the Arcos paper, they did seem to find a slightly higher elution rate with the addition of the PLA. Both papers reported a robust apatite-like formation on the surface of the composite material, demonstrating strong bioactivity despite the presence of the PMMA and antibiotic. It should be noted that the composites from both of these studies had relatively low percentages of PMMA by weight: Arcos $32 \mathrm{wt} . \%$, Ragel 27 wt.\%. From these low PMMA cement composites, they were able to deliver around $80 \%$ of the incorporated gentamicin over 48 hours. Neither of these studies made a comparison of antibiotic release rates between PMMA and the glass/PMMA composite to evaluate the beneficial effects on elution from glass addition. In our study, we did make a head-to-head comparison to controls and were able to demonstrate a substantial increase in elution due to the presence of the bioactive glass. Although no mechanical testing was reported in these two papers, it is likely that due to high filler content the strength would have decreased very rapidly in solution, rendering these composites suitable for bone fillers and beads but not for load-bearing applications.

Fernandez et al. evaluated the effect of adding acrylic-phosphate glasses $\left(\mathrm{P}_{2} \mathrm{O}_{5}-\mathrm{CaO}-\mathrm{Na}_{2} \mathrm{O}\right)$ to PMMA bone cement on vancomycin elution.[46] Comparing their results to control ( $0 \mathrm{wt} \%$ glass), they found no increase in drug release after adding $30 \%$ glass by weight but did find that $60 \mathrm{wt} \%$ and $70 \mathrm{wt} \%$ yielded substantial increases in drug release. While mechanical testing on the composites without vancomycin prior to soaking showed little change in the strength due to glass incorporation, no data was given about strength of the composites after soaking and elution. Although unreported, it is likely that the high amounts of water soluble acrylic-phosphate led to a rapid decrease in the mechanical strength of the composite. In our study, we used a relatively low amount of glass filler (13-15 wt \%) in order to maintain compressive strength above $70 \mathrm{MPa}$ while still detecting significant increases in vancomycin elution above control.

\section{Study Limitations}

Limitations of our study include those common to in vitro elution studies. The nature of in vitro studies do not necessarily reflect in vivo or clinical conditions, and they do not address the issue of how much elution is enough. Elution was carried out in a defined volume static solution, which is not necessarily the case within the context of the human body. Due to differences in hydrostatic pressure against the cement surface as well as the solubility of any drug within the human body, an absolute comparison to this environment with in vitro elution data cannot be made. The goal of this study was to directly quantify the augmentation of vancomycin elution from PMMA due to the addition of a bioactive filler material.

\section{Conclusions}

Borate bioactive glass addition to commercial PMMA bone cement was shown to be an effective bioactive filler for the purpose of increasing vancomycin from the cement. Even with a modest glass filler wt.\% relative to other methods, vancomycin release is significantly increased both during initial burst release and over the subsequent lower release period. Importantly, the compressive strength of these glass-cement composites are able to achieve orthopedic weight-bearing applicability by maintaining strength over $70 \mathrm{MPa}$, even after soaking for as long as 8 weeks. 


\section{Acknowledgments}

This work was partially supported by the Marc A. and Elinor J. Asher Orthopedic Research Endowment.

\section{Competing Interests}

The authors have declared that no competing interest exists.

\section{References}

1. Ong KL, Kurtz SM, Lau E, Bozic KJ, Berry DJ, Parvizi J. Prosthetic Joint Infection Risk After Total Hip Arthroplasty in the Medicare Population. The Journal of Arthroplasty. 2009;24(6 Suppl):105-109.

2. Kurtz SM, Ong KL, Lau E, Bozic KJ, Berry D, Parvizi J. Prosthetic joint infection risk after TKA in the Medicare population. Clinical orthopaedics and Related Research. 2010;468(1):52-56.

3. Buchholz HW, Englebrecht H. Uber die Depotwirkung einiger Antibiotika bei Vermischung mit dem Kunstharz Palacos. Chirurg. 1970;41:511-515.

4. Jiranek WA, Hanssen AD, Greenwald AS. Antibiotic-Loaded Bone Cement for Infection Prophylaxis in Total Joint Replacement. Journal of Bone and Joint Surgery. 2006;88(11):2487-2500.

5. Kiaer S. Hip Arthroplasty with Acrylic Prosthesis. Acta Orthopaedica Scandinavica. 1952;22(2):126-140.

6. Bistolfi A, Massazza G, Verne E, et al. Antibiotic-loaded Cement in Orthopedic Surgery: a Review. ISRN Orthopedics. 2011;2011:290851.

7. Kusy RP, Whitley JQ, Kalachandra S. Mechanical Properties and Interrealationships of Poly(Methyl Methacrylate) following hydration over saturated salts. Polymer. 2001;42(6):2585-2595.

8. N'Diaye M, Pascaretti-Grizon F, Massin P, Basle MF, Chappard D. Water absorption of poly(methyl methacrylate) measured by vertical interference microscopy. Langmuir : the ACS journal of surfaces and colloids. 2012;28(31):11609-11614.

9. Ayre WN, Denyer SP, Evans SL. Ageing and Moisture Uptake in Polymethyl Methacrylate (PMMA) Bone Cements. J Mech Behav Biomed Mater. 2014;32(100):76-88.

10. Miller R, McLaren A, Leon C, McLemore R. Mixing method affects elution and strength of high-dose ALBC: a pilot study. Clinical Orthopaedics and Related Research. 2012;470(10):2677-2683.

11. Brock HS, Moodie PG, Hendricks KJ, McIff TE. Compression strength and porosity of single-antibiotic cement vacuum-mixed with vancomycin. The Journal of Arthroplasty. 2010;25(6):990-997.

12. Amin TJ, Lamping JW, Hendricks KJ, McIff TE. Increasing the elution of vancomycin from high-dose antibiotic-loaded bone cement: a novel preparation technique. The Journal of Bone and Joint Surgery. American volume. 2012;94(21):1946-1951.

13. Penner M, Masri BA, Duncan CP. Elution Characteristics of Vancomycin and Tobramycin Combined in Acrylic Bone-Cement. The Journal of Arthroplasty. 1996;11(8):939-944.

14. Shen SC, Ng WK, Dong YC, Ng J, Tan RB. Nanostructured material formulated acrylic bone cements with enhanced drug release. Mater Sci Eng C Mater Biol Appl. 2016;58:233-241.

15. Slane JA, Vivanco JF, Rose WE, Squire MW, Ploeg HL. The influence of low concentrations of a water soluble poragen on the material properties, antibiotic release, and biofilm inhibition of an acrylic bone cement. Mater Sci Eng C Mater Biol Appl. 2014;42:168-176.

16. Tunney MM, Brady AJ, Buchanan F, Newe C, Dunne NJ. Incorporation of chitosan in acrylic bone cement: effect on antibiotic release, bacterial biofilm formation and mechanical properties. Journal of Materials Science. Materials in Medicine. 2008;19(4):1609-1615.

17. Jones JR. Review of bioactive glass: from Hench to hybrids. Acta Biomaterialia. 2013;9(1):4457-4486.

18. Hench LL, Splinter RJ, Allen WC, Greenlee TK. Bonding Mechanisms at the Interface of Ceramic Prosthetic Materials. Journal of Biomedical Materials Research. 1971;5(6):117-141.

19. Hench LL. The Story of Bioglass. J Mater Sci Mater Med. 2006;17(11):967-978.

20. Rahaman MN, Liang $W$, Day DE. Preparation and Bioactive Characteristics of Porous Borate Glass Substrates. Advances in Bioceramics and Biocomposites. 2005; Chapter 1:3-10.

21. Huang W, Day DE, Kittiratanapiboon K, Rahaman MN. Kinetics and mechanisms of the conversion of silicate (45S5), borate, and borosilicate glasses to hydroxyapatite in dilute phosphate solutions. J Mater Sci Mater Med. 2006;17(7):583-596.
22. Gu Y, Huang W, Rahaman MN, Day DE. Bone regeneration in rat calvarial defects implanted with fibrous scaffolds composed of a mixture of silicate and borate bioactive glasses. Acta Biomaterialia. 2013;9(11):9126-9136.

23. Bi L, Rahaman MN, Day DE, et al. Effect of bioactive borate glass microstructure on bone regeneration, angiogenesis, and hydroxyapatite conversion in a rat calvarial defect model. Acta Biomaterialia. 2013;9(8):8015-8026

24. Fu Q, Rahaman MN, Fu H, Liu X. Silicate, borosilicate, and borate bioactive glass scaffolds with controllable degradation rate for bone tissue engineering applications. I. Preparation and in vitro degradation. Journal of Biomedical Materials Research. Part A. 2010;95(1):164-171.

25. Rahaman $\mathrm{MN}$, Day $\mathrm{DE}$, Bal $\mathrm{BS}$, et al. Bioactive glass in tissue engineering. Acta Biomaterialia. 2011;7(6):2355-2373.

26. Rahaman MN, Bal BS, Huang W. Review: emerging developments in the use of bioactive glasses for treating infected prosthetic joints. Materials science \& engineering. C, Materials for biological applications. 2014;41:224-231.

27. Ottomeyer M, Mohammadkah A, Day D, Westenberg D. Broad-Spectrum Antibacterial Characteristics of Four Novel Borate-Based Bioactive Glasses. Advances in Microbiology. 2016;6(10):776-787.

28. Kaya S, Cresswell M, Boccaccini AR. Mesoporous silica-based bioactive glasses for antibiotic-free antibacterial applications. Materials Science \& Engineering. C, Materials for Biological Applications. 2018;83:99-107.

29. Arcos D, Ragel CV, Vallet-Regi M. Bioactivity in glass/PMMA composites used as drug delivery system. Biomaterials. 2001;22:701-708.

30. Kaur G, Pandey OP, Singh K, Homa D, Scott B, Pickrell G. A review of bioactive glasses: Their structure, properties, fabrication and apatite formation. Journal of Biomedical Materials Research. Part A. 2014;102(1):254-274.

31. ISO 5833:2002 - Implants for Surgery - Acrylic Resin Cements. International Organization for Standardization, Geneva, Switzerland.

32. ASTM. Standard Specification for Acrylic Bone Cement. ASTM International. 2016.

33. Chang Y, Chen WC, Hsieh PH, et al. In vitro activities of daptomycinvancomycin-, and teicoplanin-loaded polymethylmethacrylate against methicillin-susceptible, methicillin-resistant, and vancomycinintermediate strains of Staphylococcus aureus. Antimicrob Agents Chemother. 2011;55(12):5480-5484.

34. Nelson CL. The Current Status of Material Used for Depot Delivery of Drugs. Clinical Orthopaedics and Related Research. 2004;427:72-78.

35. Hanssen AD. Local Antibiotic Delivery Vehicles in the Treatment of Musculoskeletal Infection. Clinical Orthopaedics and Related Research. 2005;437:91-96.

36. Tunney MM, Ramage G, Patrick S, Nixon JR, Murphy PG, Gorman SP. Antimicrobial Susceptibility of Bacteria Isolated from Orthopedic Implants following Revision Hip Surgery. Antimicrobial Agents and Chemotherapy. 1998;42(11):3002-3005.

37. Neut D, van de Belt H, Stokroos I, van Horn JR, van der Mei HC, Busscher HJ. Biomaterial-associated infection of gentamicin-loaded PMMA beads in orthopaedic revision surgery. Journal of Antimicrobial Chemotherapy. 2001;47(6):885-891.

38. McConoughey SI, Howlin RP, Wiseman J, Stoodley P, Calhoun JH. Comparing PMMA and calcium sulfate as carriers for the local delivery of antibiotics to infected surgical sites. J Biomed Mater Res B Appl Biomater. 2015;103(4):870-877.

39. van de Belt $H$, Neut D, Uges DRA, et al. Surface roughness, porosity and wettability of gentamicin-loaded bone cements and their antibiotic release. Biomaterials. 2000;21(19):1981-1987.

40. Anagnostakos K, Kelm J. Enhancement of Antibiotic Elution From Acrylic Bone Cement. J Biomed Mater Res B Appl Biomater. 2009;90(1):467-475.

41. Liu X, Rahaman MN, Day DE. Conversion of melt-derived microfibrous borate (13-93B3) and silicate (45S5) bioactive glass in a simulated body fluid. J Mater Sci Mater Med. 2013;24(3):583-595.

42. Fu Q, Rahaman MN, Bal BS, Bonewald LF, Kuroki K, Brown RF. Silicate, borosilicate, and borate bioactive glass scaffolds with controllable degradation rate for bone tissue engineering applications. II. In vitro and in vivo biological evaluation. Journal of Biomedical Materials Research. Part A. 2010;95(1):172-179.

43. Jia WT, Fu Q, Huang WH, Zhang CO, Rahaman MN. Comparison of Borate Bioactive Glass and Calcium Sulfate as Implants for the Local Delivery of Teicoplanin in the Treatment of Methicillin-Resistant Staphylococcus aureus-Induced Osteomyelitis in a Rabbit Model. Antimicrob Agents Chemother. 2015;59(12):7571-7580.

44. Huiskes $R$, Weinans $H$, van Rietbergen B. The Relationship Between Stress Shielding and Bone Resorption Around Total Hip Stems and the 
Effects of Flexible Materials. Clinical Orthopedics and Related Research. 1992;274:124-134.

45. Ragel CV, Vallet-Regí M. In vitro bioactivity and gentamicin release from glass-polymer-antibiotic composites. Journal of Biomedical Materials Research. 2000;51(3):424-429.

46. Fernández M, Méndez JA, Vázquez B, et al. Acrylic-phosphate glasses composites as self-curing controlled delivery systems of antibiotics. Journal of Materials Science: Materials in Medicine. 2002;13(12):1251-1257. 